\title{
Multicomponent complex formation between pyrimethamine, cyclodextrins and water-soluble polymers
}

\author{
Leticia Norma Carpentieri Rodrigues ${ }^{1,2^{*}}$, Michelle Georges Issa ${ }^{4}$, Ana Carolina Cavassin \\ Asbahr $^{2}$, Marco Aurélio Carvalho Silva ${ }^{3}$ and Humberto Gomes Ferraz ${ }^{4}$ \\ ${ }^{1}$ Departamento de Ciências Exatas e da Terra; Universidade Federal de São Paulo; Rua Arthur Riedel, 275; \\ Diadema - SP - Brasil. ${ }^{2}$ Laboratório de Tecnologia Farmacêutica; Universidade Federal do Paraná; Curitiba - PR \\ - Brasil. ${ }^{3}$ Universidade Positivo; Curitiba - PR - Brasil. ${ }^{4}$ Faculdade de Ciências Farmacêuticas; Universidade de \\ São Paulo - SP - Brasil
}

\begin{abstract}
The combined effect of hydroxypropyl- $\beta$-cyclodextrin (HP $\beta C D)$ and polyvinylpyrrolidone (PVP) or sodium carboxymethylcellulose $(C M C)$ on the solubility of pyrimethamine (PYR) was studied. Equimolar PYR-HPBCD solid systems, in the presence or the absence of $0.25 \%(w / v)$ PVP or $0.10 \%(w / v)$ CMC were prepared by coevaporation or freeze-drying, and characterized by differential scanning calorimetry, X-ray diffraction analysis and dissolution profile. Phase-solubility analysis was used to investigate the interactions in aqueous solution between PYR and HPBCD, in the absence or presence of polymers, which showed a linear increase of PYR solubility depending on the concentration of HP $\beta C D$. The presence of polymer did not alter the stoichiometry of the complexes. DSC results were indicative of complexation, due to the loss of the characteristic endothermic peak of PYR. X-ray diffraction analysis confirmed the DSC results. Binary and ternary complexes showed higher dissolution rate when compared with the pure drug.
\end{abstract}

Key words: Pyrimethamine; $\mathrm{HP} \beta \mathrm{CD}$; inclusion complexes

\section{INTRODUCTION}

The pharmaceutical importance of CDs (cyclodextrins) as excipients, used for improving the formulation performance, is recognized by many regulatory agencies (Mura et al., 2001). However, for many reasons that include cost, production and toxicology, the amount of CDs that could be incorporated in the pharmaceutical products is limited (Valero et al., 2004; Loftsson and Brewster, 1996). When the complexation efficiency is low and a large amount of CD is required to obtain solid or liquid dosage forms, improving the complexation capacity is very important. Several studies have described the positive effect of addition of small quantities of water-soluble polymers in drug/cyclodextrin complexes, improving the complexation efficiency and the CD solubility (Mura et al., 2001; Partika et al., 2001; Ribeiro et al., 2003).

Loftsson and cols (1994) observed a significant increase (about 1.7 fold) in the solubility of many drugs by the addition of small amounts $(0.25 \%)$ of PVP (polyvinylpyrrolidone), CMC (sodium carboxymethylcellulose) or HPMC (hydroxypropyl methylcellulose). Mura et al.,

*Author for correspondence: leticia.carpentieri@unifesp.br 
(2001) observed an increase of dissolution rate of naproxen when complexed in a ternary system naproxen/HP $\beta C D / P V P$. The combined use of PVP and $\mathrm{HP} \beta C D$ resulted in a synergistic increasing effect of the aqueous solubility of NAP (120 times that of the pure drug).

Pyrimethamine (PYR) (Fig. 1) is a diaminopyrimidine used in combination with sulfonamides, usually sulfadoxine or dapsone. It exerts antimalarial activity by inhibiting the plasmodial dihydrofolate reductase, thus indirectly blocking the synthesis of nucleic acids in malaria parasite. It is a slow-acting blood schizontocide, and could also be used for the treatment of toxoplasmosis (Greenwood, 2008). Due to its low water solubility $\left(0.0273 \mathrm{mg} \cdot \mathrm{mL}^{-1}\right)$, high doses of PYR are required to provide a satisfactory inhibition of proliferation of the parasite. Low soluble drugs show bioavailability problems and are unpredictable and slowly absorbed when compared with the drugs more soluble in water (Carrier et al., 2007). Several studies on the complexation of pyrimethamine with different CDs have reported clear proof of these advantages (Araújo et al., 2007; Asbhar et al., 2009; Jansook, Loftsson, 2009). Little attention has been focused on the use of third components, such as watersoluble polymers, for improving the properties of drug:CD complexes. The aim of this work was to prepare and to characterize the inclusion complexes between pyrimethamine (PYR) and hydroxypropyl- $\beta$-cyclodextrin (HP $\beta C D$ ) in the presence or absence of water-soluble polymers polyvinylpyrrolidone (PVP) and sodium carboxymethylcellulose (CMC).<smiles>CCc1nc(N)nc(N)c1-c1ccc(Cl)cc1</smiles>

Figure 1 - Chemical structure of PYR.

\section{MATERIAL AND METHODS}

\section{Material}

Pyrimethamine was purchased from Roche S.A., hydroxypropyl- $\beta$-cyclodextrin was kindly provided by Chemyunion. Polyvinylpyrrolidone (Plasdone K25) and sodium carboxymethylcellulose was purchased from ISP and Wollf-Celullolsics, respectively. All other reagents and solvents used were of analytical grade.

\section{Inclusion Complex Preparation}

Binary and ternary complexes were obtained by two different methods: coevaporation (COE) and freeze-drying $(\mathrm{LPh})$. Equimolar quantities of PYR and $\mathrm{HP} \beta C D$ were dispersed in water. Dispersions were homogenized on a magnetic stirrer and evaporated at $40^{\circ} \mathrm{C}$ for $56 \mathrm{~h}$ or frozen in an ethanol immersion bath at $-50^{\circ} \mathrm{C}$ (Freezone ${ }^{\circledR}$ model 79490, Shell Freezer) and then freeze-drying (Lyph-lock 6 apparatus). Ternary systems were obtained in the same way, but the equimolar quantities of PYR and HP $\beta C D$ were dispersed in $0.25 \%(\mathrm{w} / \mathrm{v})$ of PVP or $0.10 \%(\mathrm{w} / \mathrm{v})$ of CMC water solutions. Physical mixtures (PM) of binary and ternary systems were prepared in the same molar ratio and compared.

\section{Phase-solubility analysis}

Phase-solubility study was conducted as described by Higuchi and Connors (1965). Excess amount of PYR was added to the aqueous solutions containing increasing concentrations of PVP or CMC $(0,0.1,0.15,0.20,0.25,0.30,0.40$ and $0.5 \%)$ or $\mathrm{HP \beta CD}(0,0.2,0.4,0.6,0.8,1.0,1.4$, 2.0, 4.0, 8.0 and $\left.10.0 \mathrm{mmol} . \mathrm{L}^{-1}\right)$ in the presence or absence of a fixed quantity of PVP $(0.25 \%)$ or CMC $(0.10 \%)$. The suspensions were equilibrated at $37{ }^{\circ} \mathrm{C}$ under mechanic stirring for $72 \mathrm{~h}$, then filtered $(0.45 \mu \mathrm{m}$ pore size $)$ and assayed by spectrophotometry (Beckman Coulter ${ }^{\circledR}$ DU 640) at $273 \mathrm{~nm}$ in triplicate. 
Differential scanning calorimetry (DSC)

DSC curves were obtained by conventional differential scanning calorimetry (DSC 50 Shimadzu) using aluminum crucibles with $3.0 \mathrm{mg}$ of samples, under dynamic nitrogen atmosphere $\left(50 \mathrm{~mL} \cdot \mathrm{min}^{-1}\right)$ and heating rate of $10^{\circ} \mathrm{C} \cdot \mathrm{min}^{-1}$ in a temperature range of 40 to $300^{\circ} \mathrm{C}$. The DSC cell was calibrated with indium $99.99 \%$ pure (m.p.

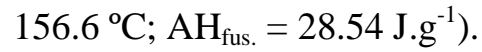

\section{X-ray diffractometry}

X-ray diffraction patterns were collected with a Shimadzu XD-6000 diffractometer in the 2 theta range at scan rate of $2^{\circ} \mathrm{min}^{-1}$, using polycrystalline silicon as reference.

\section{Dissolution Profile}

Binary and ternary system in an amount equivalent to $25 \mathrm{mg}$ of PYR were placed in hard gelatin capsules and compared with capsules containing $25 \mathrm{mg}$ of PYR. Dissolution profiles were performed in a Hanson Research ${ }^{\circledR}$ dissolutor (model SR II 6), according to USP 31 monograph (United States Pharmacopeia, 2009): apparatus 2 (paddle), in $900 \mathrm{~mL}$ of $\mathrm{HCl} 0.01 \mathrm{~N}\left(37 \pm 0.5^{\circ} \mathrm{C}\right)$ and stirred at $50 \mathrm{rpm}$. At fixed time intervals (5, 10, $15,20,25,35$ and $45 \mathrm{~min}$ ), samples were collected, filtered (pore size $=45 \mu \mathrm{m}$ ) and the drug was quantified in a spectrophotometer (Beckman
Coulter ${ }^{\circledR}$ UV-VIS DU 640), using $1 \mathrm{~cm}$ quartz glass cuvette at $273 \mathrm{~nm}$. Values obtained were corrected considering the amounts collected and expressed in percentage of drug dissolved versus the time. Sinkers were employed to avoid capsule flotation in dissolution vessel.

\section{RESULTS AND DISCUSSION}

\section{Phase-solubility analysis}

The addition of water-soluble polymers to an aqueous solution of drug and $\mathrm{CD}$ is frequently associated to the increase of the complex stability constant $\left(\mathrm{K}_{\mathrm{C}}\right)$ and to an improvement of complexation efficiency. Therefore, less $\mathrm{CD}$ is necessary to complex the same amount of drug (Loftsson, Másson e Sigurjónsdóttir, 1999). When polymer and $\mathrm{CD}$ are present in a system, it is expected to increase the solubility greater than for each individual component, demonstrating a synergistic effect with the formation of a new kind of complex, where $\mathrm{CD}$ is the complexing agent and the polymer, a co-complexant. Phasesolubility diagrams of PYR in HP $\beta C D$ solutions in the presence or absence of water soluble polymers [0.25\% (w/v) PVP or $0.10 \%(w / v)$ CMC] are presented in Figure 2.

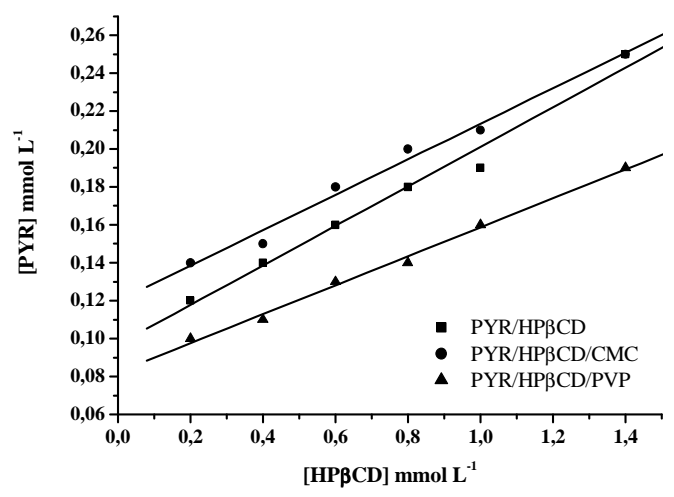

Figure 2 - Phase-solubility diagrams for PYR at room temperature in the presence of HP $\beta C D$ without polymers and with $0.25 \%$ (w/v) PVP or $0.10 \%(w / v) ~ C M C$.

Phase solubility diagrams showed a linear increase of PYR solubility as a function of HPßCD concentration and were all Higuchi $A_{L}$ type, indicating the formation of first order complex relative of $\mathrm{CD}$ and of order 1 or superior for the guest-molecule. Considering the formation of a complex with 1:1 stoichiometry, first order relative to $\mathrm{CD}(\mathrm{n}=1)$ and order 1 relative to PYR, the system could be represented by the following chemical equation:

$m P Y R+n \mathrm{HP} \beta \mathrm{CD} \longleftrightarrow{ }_{c} c P Y R_{n}-C D_{n}$ 
and $\mathrm{K}_{\mathrm{C}}$ value can be determined by the Higuchi and Connors equation (1965):

$$
K_{C}=\frac{\text { slope }}{S_{0}(1-\text { slope })}
$$

where $S_{0}$ is the intrinsic solubility of guestmolecule.

A range of stability constant values of 0 to approximately $100.000 \mathrm{~mol} . \mathrm{L}^{-1}$ has been reported for cyclodextrins complexes in the literature, with 0 corresponding to the absence of stability (Rajewski and Stella, 1996). According to Pitha et al. (1986), only complexes showing stability constants $\left(\mathrm{K}_{\mathrm{C}}\right)$ between 200 to $5000 \mathrm{~mol} . \mathrm{L}^{-1}$ could have practical applications; consider that label complexes conduct to a fast drug release and much stable complexes origin incomplete or delayed release. However, $\mathrm{K}_{\mathrm{C}}$ value is greatly affected by the precision of the solubility in the intercept. According to Loftsson et al. (2005), intrinsic solubility $\left(\mathrm{S}_{0}\right)$ should be the same of the intercept solubility $\left(\mathrm{S}_{\text {int }}\right)$ defined by the equation, but for the drugs whose solubility is less than $0.1 \mathrm{mg} \cdot \mathrm{mL}^{-1}$, negative deviations of intrinsic solubility are observed. The value of intrinsic solubility found for PYR was $0.1096 \mathrm{mM}\left(0.0273 \mathrm{mg} \cdot \mathrm{mL}^{-1}\right)$. Values of $-0.1160,0.0927$ and -0.2490 were obtained from the relation $\left(\mathrm{S}_{\text {int }}-\mathrm{S}_{0}\right) / \mathrm{S}_{\text {int }}$ to the complexes PYR/HP $\beta C D, P Y R / H P \beta C D / C M C$ and $\mathrm{PYR} / \mathrm{HP} \beta \mathrm{CD} / \mathrm{PVP}$, respectively. In order to not aggregate the errors to $K_{C}$ values, the $S_{0}$ obtained experimentally was used to calculate the constant $\left(K_{C}\right)$. Table 1 shows the $S_{\text {int }}$ values, as well as the slope calculated according to phase solubility diagrams and stability constant $\left(\mathrm{K}_{\mathrm{C}}\right)$ for binary and ternary systems.

Table 1 - Values of intrinsic solubility $\left(\mathrm{S}_{\mathrm{int}}\right)$, slope of phase solubility diagrams and stability constants $\left(\mathrm{K}_{\mathrm{C}}\right)$ of PYR binary and ternary systems.

\begin{tabular}{|c|c|c|c|}
\hline Systems & $S_{\text {int }}\left(\mathbf{m g} \cdot \mathbf{m L}^{-1}\right)$ & Slope & $\mathbf{r}^{2}$ \\
\hline PYR/HP $\beta C D$ & 0.0241 & 0.1043 & 0.9911 \\
\hline PYR/HP $\beta C D / C M C$ & 0.0298 & 0.0936 & 0.9933 \\
\hline PYR/HP $\beta C D / P V P$ & 0.0205 & 0.0764 & 0.9971 \\
\hline
\end{tabular}

The presence of polymer did not alter the stoichiometry of the complex formed, which was $1: 1$ for the PVP and CMC, as occurred in the absence of polymers. The stability constants obtained showed no increase in complexing PYR/HP $\beta C D$ in the presence of polymers. This behavior was in good agreement with the data obtained for other drugs (acetazolamide, alprazolam, carbamazepine, dexamethazone, ethoxyzolamide, methazolamide, sulphametoxazole) in the presence of different polymers (Loftsson and Friodriksdottir, 1998), where $\mathrm{K}_{\mathrm{C}}$ values were only modified after certain types of treatment.

Considering that $\mathrm{K}_{\mathrm{C}}$ for a same drug and a same cyclodextrin could vary according to the method for determination. This constant is only apparent and is necessary to use other ways to evaluate the complexation efficiency. According to Loftsson et al (2007), the best method to evaluate cyclodextrins and their potential for drug solubilization is the use of CE - complexation efficiency, that could be calculated just using the slope value. Based on this value, the drug: $\mathrm{CD}$ ratio can be determined, as well as the increase in the formulation bulk in a solid dosage form.

The solubilizing efficiency is determined by either the slope of the phase-solubility profile or the complex to free cyclodextrin concentration ratio, which is referred as the complexation efficiency (CE) (Loftsson et al., 1999):

$\mathrm{CE}=S_{0} \cdot K_{1: 1}=[\mathrm{D} / \mathrm{CD}] /[\mathrm{CD}]=$ Slope $/(1-$ Slope $)$

where $[D / C D]$ is the concentration of dissolved complex, $[\mathrm{CD}]$ the concentration of dissolved free cyclodextrin and Slope is the slope of the phase solubility profile. The $\mathrm{CE}$ can be used to calculate the D:CD ratio, which can be correlated to the expected increase in formulation bulk:

$\mathrm{D}: \mathrm{CD}=1:(1+1 / \mathrm{CE})$

$\mathrm{CE}$ values and drug: $\mathrm{CD}$ molar ratio for binary and ternary system are presented in Table 2 . 
Table 2 - Complexation efficiency (CE), molar ratio (D:CD) and formulation bulk (FB, mg) for binary and ternary systems.

\begin{tabular}{|c|c|c|c|}
\hline System & $\mathbf{C E}$ & D:CD (molar) & FB (mg) \\
\hline PYR:HP $\beta C D$ & 0.1164 & $1: 10$ & 1407 \\
\hline PYR:HPßCD:CMC & 0.1032 & $1: 11$ & 1547 \\
\hline PYR:HP $\beta C D: P V P$ & 0.0828 & $1: 13$ & 1829 \\
\hline
\end{tabular}

CE values are independent of $S_{0}$ and $S_{\text {int. The mean }}$ value for $C E$ in pure water was 0.1164 for $\mathrm{HP} \beta C D$ (Table 2) indicating that on the average, only about one out of every $10 \mathrm{HP} \beta C D$ molecules in the solution were forming a water-soluble complex with the pyrimethamine, assuming 1:1 drug/HP $\beta C D$ complex formation. The CE values in Table 2 showed that on an average, addition of polymers to the aqueous complexation media decreased the complex to free cyclodextrin molar ratio from $1: 10$ to about $1: 11$ or $1: 13$. The correlation between the increase in the bulk formulation and molecular weights of the cyclodextrin $\left(\mathrm{MW}_{\mathrm{CD}}\right)$ and the drug $\left(\mathrm{MW}_{\text {Drug }}\right)$, and the value of CE (Loftsson et al., 2007) would then be:

Increase in Formulation bulk $=$

$$
\mathrm{MW}_{\mathrm{CD}} / \mathrm{MW}_{\text {Drug }} \mathrm{x}(1+1 / \mathrm{CE})
$$

The new formulation bulk can be found by multiplying the number obtained with the drug dose $(25 \mathrm{mg})$. The MW of the pyramithamine and natural HPßCD are 248.72 Dalton and 1.400 Dalton, respectively. The new formulation bulk value is presented in Table 2.

The use of cyclodextrins in solid dosage forms, in particular, is limited to low doses with relatively large stability constants due to the relatively large size of cyclodextrins molecules and mass and size limitations for oral dosing. Low doses are required for practical use of cyclodextrins in traditional oral dosage forms (tablets, capsules). Drug:CD ratio are also limited by practical dosage forms size. The molar ratio of Drug:CD should be in the range of 1:1 to 1:20 (Carrier et al., 2007).

Diferential scanning calorimetry

Figure 3 shows the thermograms for pure drug, $\mathrm{HP} \beta C D$, physical mixtures, binary and ternary systems. The DSC curve for PYR showed an endothermic event at $242{ }^{\circ} \mathrm{C}$ corresponding to drug melting point. DSC curves for both binary systems, $\mathrm{B}_{\mathrm{LPh}}$ and $\mathrm{B}_{\mathrm{COE}}$ showed an endothermic event between 135 and $160{ }^{\circ} \mathrm{C}$, characteristic of dehydration, and another endothermic event at $242^{\circ} \mathrm{C}$, referent to drug melting point. The same events were observed for ternary systems prepared with CMC - $\mathrm{T}_{\mathrm{LPh}}$ and $\mathrm{T}_{\mathrm{COE}}$ - an endothermic event between 135 and $160^{\circ} \mathrm{C}$, characteristic of dehydration and another at $240^{\circ} \mathrm{C}$, referent to PYR melting point. For the ternary systems prepared with PVP ( $\mathrm{T} \mathrm{PVP}_{\mathrm{LPh}}$ and $\mathrm{T} \mathrm{PVP}_{\mathrm{COE}}$ ); however, DSC curves showed only the dehydration endothermic event between 100 and $147^{\circ} \mathrm{C}$. As the thermal event referent to drug melting point was suppressed, the formation of true inclusion complexes for these systems could be suggested.

\section{X-ray diffraction}

X-ray diffraction is a simple and useful method to detect the complex formation between drug and cyclodextrin. Diffratograms corresponding to PYR, HP $\beta C D$ and physical mixtures PYR/HP $\beta C D$ in the presence or absence of CMC and PVP and for binary and ternary coevaporated and freezedrying systems are shown in Figure 4.

Diffraction patterns showed high intensity at $12.253^{\circ}, 18.023^{\circ}$ and $26.345^{\circ}(2 \theta)$, indicating the crystallinity of PYR, while an amorphous pattern was observed for HP $\beta C D, C M C$ and PVP.

Physical mixtures showed the presence of low intensity reflections, characteristic of crystallinity of free drug. Diffratograms referents of all the binary and ternary systems with CMC showed a certain degree of amorphization, independent to the method of preparation. Only ternary systems with PVP showed complete amorphization, suggesting the formation of inclusion complexes. 

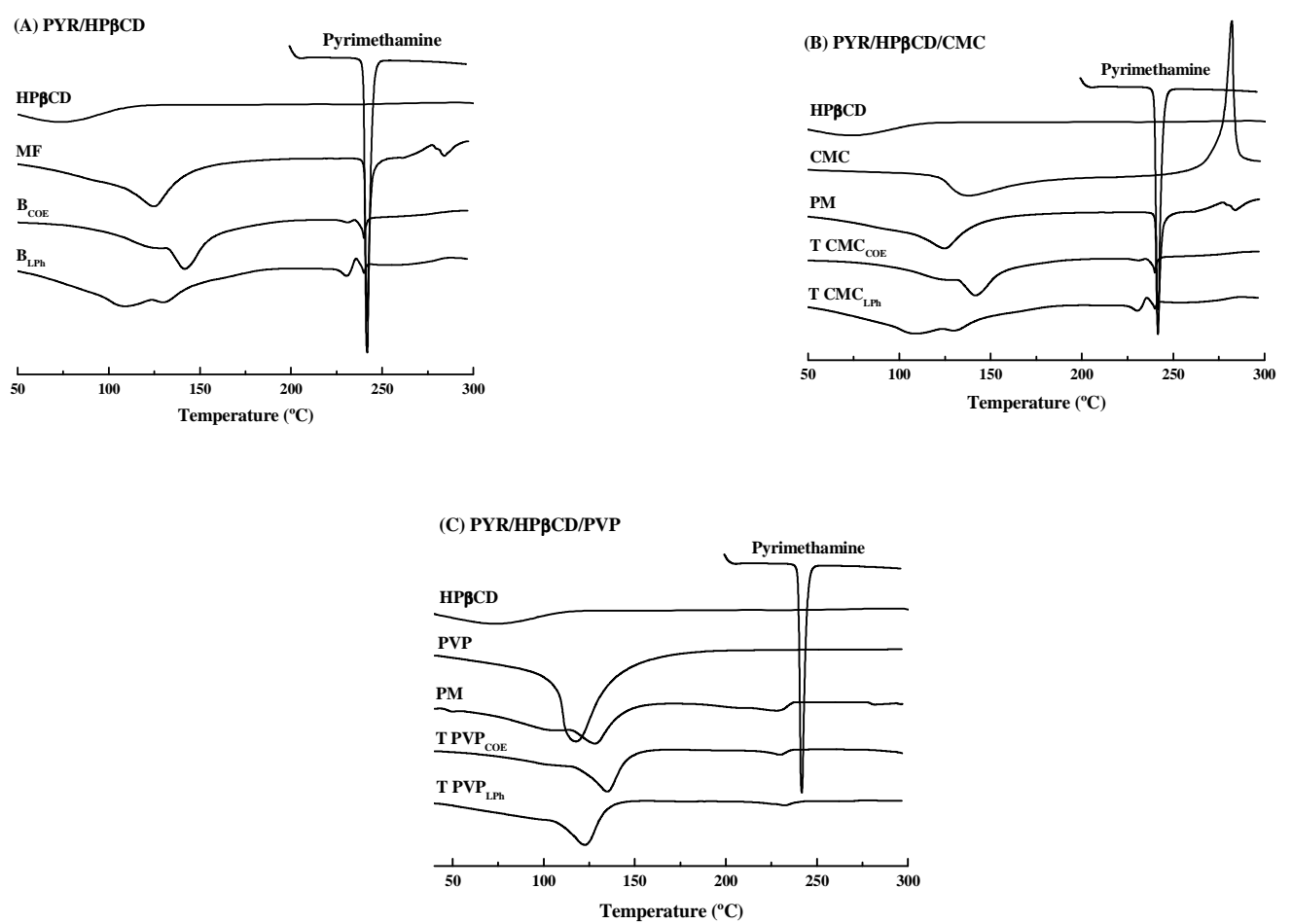

Figure 3 - DSC curves of PYR, HP $\beta C D$, polymers PVP and CMC, physical mixtures (PM), coevaporated (COE) and freeze-drying ( $\mathrm{LPh}$ ) binary $(\mathrm{B})$ and ternary $(\mathrm{T})$ systems obtained in dynamic nitrogen atmosphere $\left(100 \mathrm{~mL} \cdot \mathrm{min}^{-1}\right)$ and rate heating $10^{\circ} \mathrm{C} \cdot \mathrm{min}^{-1}$.

(A) PYR/HPBCD

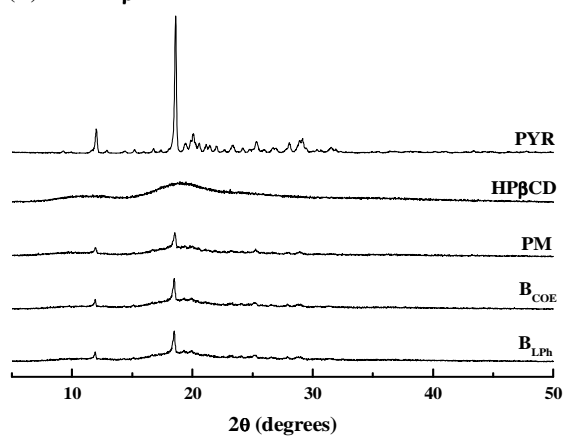

(B) PYR/HPßCD/CMC

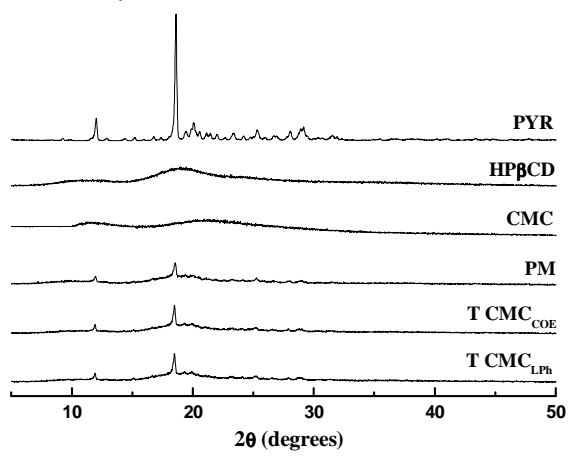

(C) PYR/HPBCD/PVP

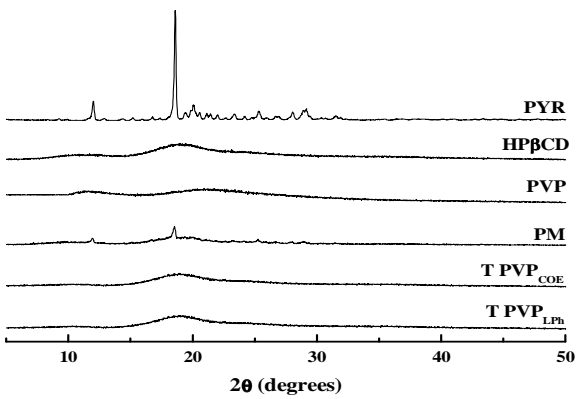

Figure 4 - XRD patterns of PYR, HP $\beta C D$, polymers PVP and CMC, physical mixtures (PM), coevaporated (COE) and freeze-drying $(\mathrm{LPh})$ binary $(\mathrm{B})$ and ternary $(\mathrm{T})$ systems. 


\section{Dissolution rate studies}

The mean dissolution profiles of PYR and corresponding binary and ternary systems are presented in Figure 5.

Binary systems obtained by coevaporation $\left(\mathrm{B}_{\mathrm{COE}}\right)$ and freeze-drying $\left(\mathrm{B}_{\mathrm{LPh}}\right)$ showed better dissolution profiles when compared to multicomponent systems. This phenomenon may be associated to the swelling effect of the polymer, and therefore to the formation of a high viscosity gel layer around powdered products, which could control the diffusivity of dissolved drug to the dissolution media (Ribeiro et al., 2005). According to Capello et al. (2001), water-soluble polymers interact with $\mathrm{CD}$ molecules or with drug-CD complexes, forming multicomponent complexes drug-CDpolymer or co-complexes - a complex formed between many drug-CD binary complexes and a linear polymer chain $\left[\left(\right.\right.$ drug-CD $\left._{n}\right]$. This aggregate hydrates in solution, increasing the diffusion layer and difficulty drug release.

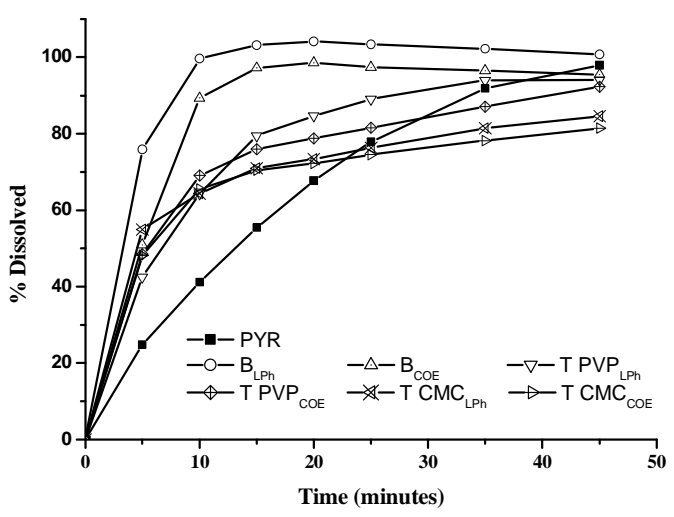

Figure 5 - Dissolution profiles of PYR and binary and ternary systems and from binary systems coevaporated $\left(\mathrm{B}_{\mathrm{COE}}\right)$ and freeze-drying $\left(\mathrm{B}_{\mathrm{LPh}}\right)$; ternary systems with $\mathrm{CMC}$ coevaporated $\left(\mathrm{T} \mathrm{CMC}_{\mathrm{COE}}\right)$ and freeze-drying $\left(\mathrm{T} \mathrm{CMC}_{\mathrm{LPh}}\right)$; ternary systems with PVP coevaporated (T PVP $\left.\mathrm{COE}_{\mathrm{C}}\right)$ and freeze-drying $\left(\mathrm{T} \mathrm{PVP}_{\mathrm{LPh}}\right)$. The vertical bars indicate the relative standard deviation associated with the mean of six capsules.

\section{CONCLUSION}

Phase-solubility diagrams showed a linear increase of PYR solubility as a function of HP $\beta C D$ concentration and were all of $A_{L}$ type, indicating the formation of first order complex relative of $\mathrm{CD}$ and of order 1 or superior for the guest-molecule. The polymers present in multicomponent system were not interacting $\mathrm{s}$ with PYR and able to improve its solubility and increase the stability of the complex. DSC curves and diffractograms indicated the complexation of PYR/HP $\beta C D / P V P$ or PYR/HP $\beta C D / C M C$, obtained by coevaporation or freeze-drying. Binary and ternary complexes showed higher dissolution rate when compared with the pure drug and could contribute for an improvement in drug bioavailability.

\section{REFERENCES}

Araujo, M.V.G.; Vieira, E.K.B.; Lazaro, G.S.; Conegero, L.S.; Ferreira, O.P.; Almeida, L.E.; Barreto, L.S.; Costa Jr, N.B.; Gimenez, L.E. (2007), Inclusion complexes of pyrimethamine in 2hydroxypropyl- $\beta$-cyclodextrin: Characterization, phase solubility and molecualr modelling. Bioorgan. Med. Chem., 15, 5752-5759.

Aronson, H. (1993), Correction factor for dissolution profile calculations. J. Pharm. Sci., 82, 1190.

Asbhar, A.C.; Franco, L.; Barison, A.; Silva, C.W.P.; Ferraz, H.G.; Rodrigues L.N.C. (2009), Binary and ternary inclusion complexes of finasteride in HP $\beta C D$ and polymers: Preparation and characterization. Bioorgan. Med. Chem., 17, 2718-2723.

Bourbigot, S.; Le Bras, M.; Daquesne, S.; Rochery, M. (2004), Recent advances for intumescent polymers. Macromol. Mater. Eng., 289, 499-511. 
Capello, B.; Carmignani, C.; Iervolino, M.; La Rotonda, M. I.; Saettone, M.F. (2001), Solubilization of tropicamide by hydroxyproyl- $\beta$-cyclodextrin and water-soluble polymers: in vitro/in vivo studies. Int. J. Pharm., 213, 75-81.

Carrier, R.L.; Miller, L.A.; Ahmed, I. (2007) The utility of cyclodextrins for enhancing oral bioavailability. $J$. Control. Release, 123, 78-99.

Greenwood, B. (2008), Progress in malaria control in endemic areas. Travel medicine and Infectious Disease, 6, 173-176.

Higuchi, T.; Connors, K. A. (1965), Advances in analytical chemistry instrumentation. WileyInterscience, New York.

Jansook, P.; Loftsson, T. (2009), CDs as solubilizers: Effects of excipients and competing drugs. Int. J. Pharm., 379, 1, 32-40.

Loftsson, T.; Frioriksdóttir, H.; Siguroardóttir, A.M.; UEDA, H. (1994), The effect of water-soluble polymers on drug-cyclodextrin complexation. Int. J. Pharm., 110, 169-177.

Loftsson, T.; Brewster, M. (1996), Pharmaceutical applications of cyclodextrins. 1. Drug solubization and stabilization. J. Pharm. Sci., 85, 1017-1025.

Loftsson, T., Fridriksdóttir, H., (1998). The effect of water-soluble polymers on the aqueous solubility and complexing abilities of -cyclodextrin. Int. J. Pharm., 163, 115-121.

Loftsson, T.; Másson, M.; Sigurjónsdóttir, J. F. (1999), Methods to enhance the complexation efficiency of cyclodextrins. STP Pharma Sci., 9, 237-242.

Loftsson, T.; Hreinsdóttir, D.; Másson, M. (2005), Evaluation of cyclodextrin solubilization of drugs. Int. J. Pharm., 302, 18-28.

Loftsson, T.; Hreinsdóttir, D., Másson, M. (2007), The complexation efficiency. Journal of J. Incl. Phenom. Macro., 57, 545-552.
Mura, P.; Faucci, M.T.; Bettinetti, G.P. (2001), The influence of polyvinilpyrrolidone on naproxen complexation with hydroxypropyl- $\beta$-cyclodextrin. Eur. J. Pharm. Sci., 13, 187-194.

Partika, M.; Au, B.H.; Evans, C.H. (2001), Cyclodextrins as phtotoxicity inhibitors in drug formulations: studies on model systems involving naproxen and $\beta$-cyclodextrin. J. Photoch. Photobio. A., 140, 67-74.

Pitha, J.; Milechi, J.; Fales, H.; Pannel, L.; Uekama, K. (1986), Hydroxypropyl- $\beta$-cyclodextrin: preparation and characterization : effects on solubility of drugs. Int. J. Pharm., 29, 73-82.

Rajewski, R.A.; Stella, V.J. (1996) Pharmaceutical applications of cyclodextrins. 2. In vivo delivery drug delivery, J. Pharm. Sci., 85, 1142-1169.

Ribeiro, L.; Ferreira, D.C.; Veiga, F.J.B. (2005) In vitro controlled release of vinpocetine-cyclodextrintartaric acid multicomponent complexes from HPMC swellable tablets. J. Control. Release, 103, p. 325-33.

Ribeiro, L.; Loftsson, T.; Ferreira, D. and Veiga, F. (2003), Investigation and physicochemical characterization of vimpocetine sulfobutyk ether $\beta$ cyclodextrin binary and ternary complexes. Chem. Pharm. Bull., 51, p.914-922.

United States Pharmacopoeia (2007), 30 ed., United States Pharmacopeial Convention, Rockville.

Valero, M.; Esteban, B.; Pelaez, R.; Rodriguez, L.J. (2004), Naproxen: Hydroxyproil- $\beta$ Cyclodextrin:Polyvinilpyrrolidone ternary Compex Formation. J. Incl. Phenom. Macro., 48, 157-163.

Received: July 05, 2010; Revised: October 21, 2010; Accepted: May 17, 2011 